\title{
GAMBARAN SELF-COMPASSION PERAWAT INSTALASI GAWAT DARURAT DI JAKARTA
}

\author{
Puspa Triani Adinda ${ }^{1}$, Christ Billy Aryanto, \& Laurensia Harini Tunjungsari \\ Fakultas Psikologi, Universitas Katolik Indonesia Atma Jaya, Jl. Jenderal Sudirman 51, Jakarta, 12930, Indonesia
}

Korespondensi:

Ie-mail: puspa.trianiadinda@gmail.com

\begin{abstract}
This study aims to explore how self-compassion shapes the experience of hospital nurses in Emergency Department (ED) in Jakarta. Previous studies demonstrated that the lack of self-compassion can increase compassion fatigue, thereby reducing the quality of services and eventually affect patients' well-being. Mixed-methods design was employed by collecting data from 77 nurses through convenient sampling. Two nurses with highest self-compassion scores and a nurse with lowest self-compassion score were interviewed for further analysis. The descriptive result indicated that selfcompassion of ED nurses in Jakarta was considerably high and only one nurse had relatively low self-compassion. There was a significant difference in self-compassion based on working time and hospital types. Qualitative analysis indicated that under stressful circumstances, nurses with high selfcompassion tended to engage with various religious activities, while the one with low self-compassion tended to be self-indulging.
\end{abstract}

\author{
Article history: \\ Received 20 March 2019 \\ Received in revised form 11 April 2019 \\ Accepted 23 May 2019 \\ Available online 26 January 2020
}

\begin{abstract}
Keywords:
emergency room;

nurse;

self-compassion
\end{abstract}

\begin{abstract}
Abstrak - Penelitian ini bertujuan untuk mengeksplorasi self-compassion perawat rumah sakit bagian Instalasi Gawat Darurat (IGD) di Jakarta. Studi sebelumnya menunjukkan bahwa kurangnya self-compassion dapat meningkatkan rasa lelah secara mental, sehingga menurunkan kualitas pelayanan rumah sakit dan dapat berdampak pada kesejahteraan pasien. Desain mixed-methods digunakan dengan mengambil 77 sampel perawat dari berbagai tipe rumah sakit melalui teknik sampel convenient. Dua perawat dengan self-compassion tertinggi dan satu perawat dengan selfcompassion terendah diwawancarai untuk analisa data kualitatif. Hasil deskriptif mengindikasikan bahwa self-compassion perawat IGD di Jakarta tergolong tinggi dan hanya satu perawat yang ditemukan memiliki self-compassion rendah. Terdapat perbedaan signifikan mengenai selfcompassion perawat berdasarkan lama bekerja dan tipe rumah sakit. Hasil kualitatif mengindikasikan bahwa ketika stres, perawat dengan self-compassion tinggi cenderung melakukan aktivitas religius, sementara perawat dengan self-compassion rendah cenderung melakukan selfindulgence.
\end{abstract}

Kata Kunci: instalasi gawat darurat; perawat; self-compassion 


\section{PENDAHULUAN}

Instalasi Gawat Darurat (IGD) merupakan area paling kritis karena dipenuhi hal-hal yang bersifat traumatis, di mana keterlambatan ataupun kesalahan penanganan dapat menimbulkan konsekuensi serius, bahkan menghilangkan nyawa pasien (Adhitya \& Untoro, 2016; Mansour \& Ratrout, 2017). Hal tersebut membuat penanganan pasien di IGD menjadi penuh tantangan, khususnya pada perawat, sebab perawat memiliki beban kerja berat dan tuntutan kerja tinggi (Adhitya \& Untoro, 2016; Craig, Hooper, Javrin \& Reimels, 2010). Perawat IGD berperan sebagai personal garis depan yang menangani pasien luka atau pendarahan, merawat, dan memberikan bantuan kehidupan pada pasien, serta dituntut selalu siap siaga untuk menangani pasien yang jumlah dan tingkat keparahannya tak terprediksi (Mandasari, Choiri, \& Sari, 2014; Mansour \& Ratrout, 2017). Perawat IGD tak jarang menemui berbagai permasalahan, seperti: masalah administrasi; miskomunikasi dengan dokter maupun rekan kerja; konflik dengan rekan kerja; komplain dari pasien; serta tingginya jumlah pasien yang tidak seimbang dengan jumlah perawat (Rahman, 2013; Prasetyo, 2017). Kejadian traumatis, beban kerja berat, tuntutan kerja tinggi, dan masalah pekerjaan membuat perawat IGD rentan stres (Mustafidz \& Mustikasari, 2013).

Studi Mulyadi, Lumintang, dan Kumaat (2015) mengenai perbedaan tingkat stres antar perawat rumah sakit di kota Manado menunjukkan bahwa stres dialami $82.4 \%$ perawat IGD dan 29.4\% perawat rawat inap. Penelitian di kota Pontianak pada tahun 2016 menunjukkan stres tinggi dialami 57.1\% perawat IGD dan 35\% perawat Intensive Care Unit (ICU) (Mallya, Rachmadi, \& Hafizah, 2016). Berdasarkan penelitian-penelitian tersebut, diketahui bahwa stres lebih banyak dialami oleh perawat IGD.

Menurut Brysiewicz dan Wentzel (2014), stres dapat memicu compassion fatigue atau kelelahan berlebihan secara fisik dan emosional yang ditandai dengan gejala sakit kepala, insomnia, mudah marah, sedih, depresi, perasaan tidak menikmati karier, sulit berempati, dan tidak mampu merawat pasien. Compassion fatigue dapat menyebabkan perawat mengalami depersonalisasi, di mana perawat tidak lagi menganggap pasien sebagai subjek yang harus dirawat, melainkan sebagai objek, sehingga menjadi berbahaya bagi pasien. Compassion fatigue juga menurunkan kinerja dan kesejahteraan psikososial perawat, serta meningkatkan intensi meninggalkan pekerjaan yang dapat menurunkan kualitas pelayanan rumah sakit.

Perawat perlu mengimbangi diri dengan self-compassion agar terhindar dari compassion fatigue. Beamount, Carson, Durkin, dan Martin (2016) menemukan bahwa self-compassion yang tinggi akan berdampak pada rendahnya compassion fatigue. Penelitian Abaci dan Arda (2013) menunjukkan bahwa 
individu dengan self-compassion tinggi lebih sedikit mengalami depresi, kecemasan, kelesuan, dan kegagalan, serta merasa lebih puas dalam pekerjaannya.

Self-compassion adalah kepedulian dan simpati terhadap diri sendiri yang mendorong individu memperlakukan dirinya dengan hangat, lembut, dan penuh kasih sayang, bahkan dalam situasi stres akibat kesulitan, penderitaan, kegagalan, dan ketidaksempurnaan diri (Neff, 2003b). Individu tidak menghindari emosi negatif, perasaan sakit, ataupun stres yang timbul akibat kesulitan, penderitaan, kegagalan, serta ketidaksempurnaan dirinya, melainkan menerima dan mengubahnya menjadi emosi positif melalui pemberian kebaikan pada diri sendiri (Neff, 2003b).

Self-compassion terdiri atas tiga dimensi, yaitu: self-kindness versus self-judgement, common humanity versus isolation, dan mindfulness versus over identification (Neff, 2003b). Self-kindness mendorong individu bersikap lembut terhadap diri sendiri dan menyadari dirinya sebagai manusia tidak luput dari ketidaksempurnaan, kegagalan, serta kesulitan hidup daripada menyalahkan diri karena hidup tidak sesuai harapan atau tidak berhasil mendapatkan yang diinginkan (Neff, 2003b). Self-judgement adalah kondisi individu tidak menerima kesulitan, rasa penderitaan, kegagalan dan ketidaksempurnaan dirinya yang menyebabkan individu dipenuhi emosi negatif(Neff, 2003b). Common humanity mendorong individu melihat dan menyadari kesulitan, penderitaan, kegagalan, dan ketidaksempurnaan diri sebagai hal manusiawi yang dialami manusia lainnya, sedangkan isolation adalah di mana individu tenggelam dalam masalahnya sendiri dan lupa bahwa orang lain memiliki masalah serupa dengannya, cenderung mengabaikan orang lain, serta merasa dirinya paling menderita (Neff, 2003b). Mindfulness mendorong individu memisahkan diri dari emosi negatif, tidak berlebihan dalam memandang masalah, dan tidak larut dalam reaktivitas negatif pikiran, sedangkan over identification adalah kondisi di mana individu cenderung memandang masalah secara berlebihan, sulit memisahkan diri dari emosi negatif, dan larut dalam permasalahan yang dialami (Neff, 2003b).

Terdapat tiga penelitian self-compassion pada perawat di Indonesia. Penelitian pertama pada perawat rawat inap rumah sakit jiwa tahun 2013 menunjukkan bahwa 74.9\% dari 183 perawat memiliki self-compassion rendah (Damayanti, 2013). Penelitian kedua pada perawat rawat inap di salah satu rumah sakit umum pemerintah tahun 2014 menunjukkan bahwa 69.5\% dari 118 perawat memiliki self-compassion rendah (Kencana, 2014). Penelitian ketiga pada perawat rawat inap di salah satu rumah sakit umum daerah tahun 2015 menunjukkan bahwa 76.5\% dari 81 perawat memiliki self-compassion rendah (Novianty, 2015). Ketiga penelitian menunjukkan bahwa self-compassion perawat Indonesia cenderung rendah.

Berdasarkan identifikasi masalah di atas, peneliti tertarik untuk meneliti self-compassion perawat IGD di Jakarta. Dengan komposisi penduduk terbanyak se-Indonesia, tingkat kecelakaan tinggi, dan sarana 
pelayanan kesehatan yang lebih lengkap daripada daerah lainnya, rumah sakit di Jakarta menjadi rumah sakit dengan aktivitas layanan kesehatan yang tinggi (Badan Pusat Statistik, 2016; Dinas Kesehatan Provinsi DKI Jakarta 2016). Tingginya jumlah pasien menambah beban kerja perawat IGD di Jakarta sehingga rentan mengalami compassion fatigue (Brysiewicz \& Wentzel, 2014; Beamount, Carson, Durkin, dan Martin, 2016; Kencana; 2014; Suardani, 2016). Oleh karena itu, perawat IGD di Jakarta perlu memiliki selfcompassion tinggi agar terhindar dari compassion fatigue akibat beratnya beban kerja yang dijalani (Kencana, 2014; Neff, 2003b).

Terdapat lima tipe rumah sakit yang dikelompokkan berdasarkan fasilitas dan kemampuan pelayanan, yaitu rumah sakit umum tipe $\mathrm{A}$, tipe $\mathrm{B}$, tipe $\mathrm{C}$, tipe $\mathrm{D}$, dan rumah sakit khusus (Menteri Kesehatan Republik Indonesia, 2010). Rumah sakit umum tipe A adalah rumah sakit pusat di wilayah provinsi dengan kategori penduduk terpadat yang menjadi tempat pelayanan rujukan tertinggi (top referral hospital), serta memiliki kapasitas tempat tidur minimal 400 buah. Rumah sakit umum tipe B adalah rumah sakit yang menampung pelayanan rujukan rumah sakit kabupaten serta memiliki kapasitas tempat tidur minimal 200 buah. Rumah sakit umum tipe C adalah rumah sakit yang menampung layanan rujukan puskesmas serta memiliki kapasitas tempat tidur minimal 100 buah. Rumah sakit umum tipe D adalah rumah sakit yang memiliki pelayanan medik dasar serta memiliki kapasitas tempat tidur minimal 50 buah. Rumah sakit khusus adalah rumah sakit yang menyelenggarakan satu macam pelayanan kedokteran (Menteri Kesehatan Republik Indonesia, 2010). Studi ini akan turut menganalisa berdasarkan tipe rumah sakit di atas.

\section{METODE}

\section{Partisipan}

Partisipan penelitian ini adalah perawat IGD di rumah sakit umum tipe A, tipe $\mathrm{B}$, tipe $\mathrm{C}$, tipe $\mathrm{D}$, dan khusus di Jakarta. Pemilihan partisipan dilakukan secara convenience, di mana peneliti memilih individu yang mudah ditemui dan sesuai dengan karakteristik partisipan yang dibutuhkan (Creswell, 2012). Data kuantitatif dengan penyebaran kuesioner diperoleh dari perawat dari rumah sakit tipe $\mathrm{B}, \mathrm{C}, \mathrm{D}$, dan khusus di Jakarta. Data kualitatif diperoleh dari tiga partisipan kuantitatif terpilih, yaitu partisipan dengan selfcompassion terendah dan tertinggi.

Salah satu partisipan (B) memiliki self-compassion rendah, yaitu seorang laki-laki berusia 31 tahun, dan telah bekerja sebagai perawat IGD di rumah sakit tempat penelitian berlangsung selama tiga bulan. Sementara dua lainnya (D \& S) memiliki self-compassion tinggi. D adalah seorang perempuan berusia 40 
tahun, telah bekerja selama delapan tahun sebagai perawat IGD. S adalah seorang perempuan berusia 28 tahun dan telah bekerja sebagai perawat IGD selama tahun. Berikut data demografi partisipan.

Tabel 1.

Gambaran Umum Partisipan untuk Analisis Kualitatif

\begin{tabular}{cccc}
\hline Karakteristik & \multicolumn{3}{c}{ Partisipan } \\
\cline { 2 - 4 } & B & $\mathrm{D}$ & $\mathrm{S}$ \\
\hline Usia & 31 tahun & 40 tahun & 28 tahun \\
Jenis Kelamin & Laki-laki & Perempuan & Perempuan \\
Lama Bekerja & 3 bulan & 8 tahun & 4 tahun \\
Self-compassion & 2.33 & 4.33 & 4.75 \\
\hline
\end{tabular}

\section{Desain}

Penelitian ini menggunakan mixed-methods dengan menggabungkan data kuantitatif dan kualitatif (Creswell, 2012). Desain yang digunakan adalah explanatory sequential, di mana pengumpulan data kuantitatif dilakukan terlebih dahulu melalui penyebaran kuesioner untuk mendapatkan gambaran umum self-compassion partisipan, serta perbandingan self-compassion partisipan dari masing-masing tipe rumah sakit. Pengumpulan data kualitatif dilakukan melalui wawancara partisipan dengan self-compassion yang tertinggi dan terendah untuk memahami fenomena, sekaligus membandingkan self-compassion dalam konteks kehidupan perawat IGD di Jakarta.

Pengambilan data kuantitatif dilakukan dengan menyebarkan kuesioner kepada seluruh partisipan yang mewakili semua tipe rumah sakit di Jakarta. Kuesioner yang digunakan adalah Self-Compassion Scale Short Form Nugraha (2017). Terdapat 12 butir soal yang diukur menggunakan Skala Likert 1-5 (1 = tidak pernah; 5 = selalu). Terdapat enam item favorable (untuk dimensi self-kindness, common humanity, dan mindfulness) dan enam item unfavorable (untuk dimensi self-judgement, isolation, dan over identification).. Berdasarkan uji validitas menggunakan korelasi Pearson, 12 butir berkorelasi secara signifikan dengan validitas berkisar .243-.762. Pengujian reliabilitas dengan Alpha Cronbach menghasilkan reliabilitas sebesar .742, di mana skor di atas .70 berarti alat ukur reliabel (Algina \& Croaker, 2008).Seluruh jawaban partisipan akan diberikan nilai dan dihitung nilai rata-ratanya. Kemudian, partisipan dikelompokkan berdasarkan tiga kategori, yakni: rata-rata 1-2.5 berarti self-compassion tergolong rendah; 2.5-3.5 berarti self-compassion tergolong rata-rata; dan 3.5-5.0 berarti self-compassion tergolong tinggi (Neff, 2003a).

Pengambilan data kualitatif dilakukan dengan mewawancarai partisipan menggunakan panduan wawancara berdasarkan teori self-compassion (Neff, 2003a) dan disesuaikan dengan konteks perawat IGD. 
Panduan wawancara diuji keterbacaannya dengan meminta pendapat individu lain yang memiliki karakteristik yang sama dengan partisipan. Hasil uji keterbacaan menunjukkan panduan wawancara sudah baik karena bahasa setiap butir pertanyaan mudah dipahami. Setelah wawancara, data dikelompokkan berdasarkan beban kerja, stres kerja, pemahaman self-compassion, serta dimensi self-compassion.

\section{Prosedur}

Pertama, peneliti mengajukan ethical clearance dan permohonan izin ke berbagai rumah sakit di Jakarta. Lalu, peneliti menyebarkan kuesioner. Data kuesioner yang terkumpul dianalisis untuk memperoleh rata-rata self-compassion partisipan dan diurutkan berdasarkan kategori rendah, sedang, dan tinggi. Partisipan dengan self-compassion paling rendah dan tinggi dipilih untuk diwawancarai.

Terdapat satu partisipan dengan self-compassion terendah dan dua partisipan dengan selfcompassion tertinggi. Wawancara ketiga partisipan dilakukan di tempat partisipan bekerja. Pelaksanaan wawancara berlangsung sekitar 40-90 menit dan dilakukan pada rentang waktu bulan Mei-Juni 2018.

\section{Teknik Analisis}

Data kuantitatif kuesioner dihitung secara statistik hingga memperoleh rata-rata self-compassion setiap partisipan, dari setiap tipe rumah sakit, serta berdasarkan faktor demografi. Uji beda pada faktor demografi dan tipe rumah sakit menggunakan uji statistik non-parametrik Mann Whitney U test dan Kruskal Wallis $H$ test. Hasil signifikan pada uji beda dilanjutkan dengan uji post hoc Dunn Bonferonni test. Data kualitatif wawancara partisipan dianalisis dengan mengaitkan transkrip wawancara dengan teori selfcompassion, sehingga gambaran self-compassion dalam teori dapat mendekati kondisi nyata kehidupan perawat IGD di Jakarta. Analisis disajikan berdasarkan kategori dan dimensi self-compassion. Terdapat perbandingan partisipan dengan self-compassion tinggi dan rendah.

\section{ANALISIS DAN HASIL}

\section{Hasil Kuantitatif}

Partisipan kuantitatif berjumlah 77 perawat IGD dari rumah sakit umum tipe $\mathrm{B}$, tipe C, tipe $\mathrm{D}$, dan khusus. Berikut rata-rata self-compassion seluruh partisipan. 
Tabel 2.

Hasil Perhitungan Nilai Rata-Rata Self-Compassion Partisipan Penelitian Secara Umum per Kategori.

\begin{tabular}{ccc}
\hline Kategori Self-Compassion & Jumlah Partisipan & Persentase (\%) \\
\hline Tinggi $(\geq 3.5)$ & 39 & $50.65 \%$ \\
Rata-rata $(2.5-3.5)$ & 37 & $48.05 \%$ \\
Rendah $(\leq 2.5)$ & 1 & $1.3 \%$ \\
Total & 77 & $100 \%$ \\
\hline
\end{tabular}

Setengah dari keseluruhan partisipan penelitian (50.65\%) memiliki self-compassion tinggi, sebagian lainnya (48.05\%) memiliki self-compassion rata-rata, dan hanya satu partisipan (1.3\%) yang memiliki selfcompassion rendah. Rata-rata keseluruhan partisipan adalah 3.57 dan dapat disimpulkan secara umum partisipan memiliki self-compassion tinggi.

Tabel 3.

Hasil Perhitungan Nilai Rata-Rata Self-Compassion Berdasarkan Faktor Demografi dari Keseluruhan Partisipan Penelitian

\begin{tabular}{cccc}
\hline Karakteristik & Kategori & Persentase (\%) & Rata-rata \\
\hline Jenis Kelamin & Laki-laki & $31.17 \%$ & 3.51 \\
Usia & Perempuan & $68.83 \%$ & 3.59 \\
(tahun) & $22-30$ & $48 \%$ & 3.62 \\
& $31-53$ & $52 \%$ & 3.51 \\
Lama Bekerja & $\leq 1$ & $9.1 \&$ & 3.21 \\
(tahun) & $1-3$ & $37.66 \%$ & 3.54 \\
& $4-6$ & $31.16 \%$ & 3.8 \\
& $7-9$ & $10.39 \%$ & 3.76 \\
\hline
\end{tabular}

Partisipan perempuan dua kali lipat lebih banyak daripada laki-laki. Partisipan usia 22-30 tahun tidak berbeda jauh dengan partisipan usia 31-53 tahun. Lama bekerja partisipan terbanyak pertama adalah yang telah bekerja di IGD di Jakarta selama 1-3 tahun dan paling sedikit dengan lama bekerja $\leq 1$ tahun.

Self-compassion berdasarkan jenis kelamin $(U=591 ; p=.624)$ dan usia $(U=671 ; p=.481)$ tidak berbeda signifikan menurut uji Mann Whitney, namun berbeda signifikan berdasarkan lama bekerja menurut uji Kruskal-Wallis $(H=14,032 ; p=.007)$. Uji post hoc dengan Dunn Bonferroni Test menunjukkan perbedaaan signifikan pada partisipan yang telah bekerja selama 4-6 tahun dengan partisipan yang telah 
bekerja selama $\geq 10$ tahun. Self-compassion partisipan cenderung meningkat mulai dari awal hingga 4-6 tahun masa bekerja, lalu cenderung menurun signifikan setelah 4-6 tahun.

Tabel 4.

Perbandingan Rata-Rata Self-Compassion Partisipan Antar Rumah Sakit

\begin{tabular}{ccc}
\hline Rumah Sakit & Rata-rata & Kesimpulan \\
\hline Tipe B & 3.85 & Tinggi \\
Tipe C & 3.34 & Rata-rata \\
Tipe D & 3.42 & Rata-rata \\
Tipe E & 3.31 & Rata-rata \\
\hline
\end{tabular}

Partisipan rumah sakit umum tipe B memiliki rata-rata self-compassion yang tinggi, sementara partisipan dari rumah sakit tipe lainnya memiliki self-compassion rata-rata. Selanjutnya, hasil uji beda dengan Kruskal Wallis $H$-Test menunjukkan adanya perbedaan signifikan $(H=16,552 ; p=.001)$ pada self-compassion partisipan antar rumah sakit, sehingga dilanjutkan dengan uji post hoc.

Uji post hoc Dunn-Bonferroni Test menunjukkan ada perbedaan self-compassion signifikan pada partisipan dari rumah sakit khusus dengan rumah sakit umum tipe $\mathrm{B}(p=.022)$, rumah sakit umum tipe $\mathrm{C}$ dengan rumah sakit umum tipe $\mathrm{B}(p=.016)$, dan rumah sakit umum tipe $\mathrm{D}$ dengan rumah sakit umum tipe B ( $p=.013)$. Dengan demikian, dapat disimpulkan bahwa self-compassion partisipan rumah sakit umum tipe B berbeda secara signifikan dengan partisipan dari rumah sakit lainnya, di mana self-compassion partisipan rumah sakit umum tipe $\mathrm{B}$ cenderung lebih tinggi daripada partisipan rumah sakit lainnya.

\section{Hasil Kualitatif}

\section{Partisipan B (Self-Compassion Rendah)}

Saat stres, B menonton televisi seharian, bermain games, memakan camilan, serta merokok. Aktivitas tersebut mengurangi stresnya, tetapi tidak dikategorikan sebagai self-compassion karena memberikan kesenangan tanpa memikirkan bahaya kesehatan yang mengancam. Menonton televisi dalam durasi panjang, bermain games, serta mengemil merupakan aktivitas kurang bergerak, sehingga meningkatkan risiko obesitas yang memicu munculnya berbagai masalah kesehatan (Kementerian Kesehatan Republik Indonesia, 2012; Rosiek, Maciejewska, Leksowski, Rosiek-Kryszewska, \& Leksowski, 2015). Merokok dapat menyebabkan individu mengalami gangguan sistem pernafasan dan penyakit kardiovaskular (Saminan, 2017). Individu dengan self-compassion akan mencari kebahagiaan secara positif (Neff, 2003). 
"Kalau lagi stres paling setelah pekerjaan nyantai aja di rumah, nonton tv seharian gitu, main game di handphone.. ngemil. Kadang juga sesekali ngerokok buat menghilangkan stres"

Reaksi B saat stres adalah marah, merasa bersalah, kecewa, malu, dan menyalahkan diri sendiri atas kegagalan ataupun kesalahan yang diperbuat sebagai pemicu stres. Jika stres timbul akibat kesalahan yang diperbuat dirinya terhadap pasien, maka B sulit memaafkan dirinya. Padahal, setiap individu mungkin mengalami kegagalan dan melakukan kesalahan yang menimbulkan stres. Reaksi tersebut merupakan selfjudgement.

"Saya melakukan kesalahan ketika bekerja dan saya mendapat teguran keras dari pihakmanajemen yang akhirnya membuat saya sangat kesal dengan diri saya. dan saya waktu itu gak berhenti nyalahin diri sendiri. Hal itu bener-bener bikin stres, tapi itu kesalahan saya sendiri. Saya kecewa dengan diri saya, saya juga malu sudah melakukan kesalahan yang harusnya tidak perlu terjadi."

B memikirkan masalah secara berulang, meskipun ia tahu dengan begitu ia menjadi semakin stres. Berpikir berulang dan negatif secara berlebih dapat membuat individu depresi (Neff, 2003b; NolenHoeksema, Wisco \& Lyubomorsky, 2008). B cenderung kesulitan memisahkan emosinya dari stres yang dialami, sehingga terkadang menyalahkan diri sendiri maupun orang lain atas stres yang dirasakannya. Reaksi tersebut adalah over identification.

"Biasanya sih kalau stres, saya suka overthinking. Nanti mungkin setelah bener-bener lelah, capek, mungkin baru di situ saya coba menghibur diri."

"Mungkin karena saya lebih sering memandang masalah itu secara subjektif kali ya? Kadang saya menyalahkan diri, kadang saya menyalahkan orang lain. Saya sih orangnya cenderung mudah terbawa emosi dan perasaan pribadi. Ya baper[bawa perasaan]-an-lah.”

Terkadang B berpikir bahwa orang di sekitarnya lebih santai, ceria, tenang, dan tidak stres jika dibandingkan dengan dirinya. Pemikiran tersebut dapat menyebabkan self-pity atau tenggelam dalam masalahnya sendiri, serta cenderung mengabaikan orang lain karena merasa dirinya paling menderita (Neff, 2003b). Reaksi tersebut merupakan isolation.

"Ada kalanya kok beberapa temen di pekerjaan kelihatannya nyantai aja gitu, anteng aja, gak terlihat punya masalah. Cuma kan mungkin hanya terlihat di luarnya aja, gak tau dalamnya seperti apa. Yang jelas ada perasaaan seperti kok orang lain lebih ceria, lebih tenang, lebih enjoy di kerjaan." 
Dimensi self-judgment, over identification, dan isolation yang merupakan kebalikan dari selfcompassion pada diri B cukup menonjol. Akan tetapi, pada konteks stres tertentu, B memunculkan selfcompassion. Stres yang berdampak merugikan diri sendiri masih memungkinkan B untuk memunculkan self-kindness dengan berpikiran positif dan memaafkan kekurangan beserta kegagalan dirinya.

\begin{abstract}
"Kalau kesalahan yang merugikan orang lain, saya lebih susah memaafkan diri saya mbak. Mungkin kalau dalam hal-hal seperti mendapatkan apa yang saya inginkan, mungkin saya masih bisa berpikir positif. Saya bisa berpikir. oh mungkin belum rejeki, mungkin ada yang lebih baik untuk saya di kemudian hari. Jadi, saya kalau untuk kesalahan yang terjadi kepada diri saya sendiri, saya gak begitu larut dalam stres atau kesedihan."
\end{abstract}

Terkadang B pun berusaha menyadari bahwa stres yang dialaminya juga dirasakan oleh orang lain di sekitarnya walau tidak sepenuhnya serupa. Dengan menghubungkan pengalaman diri sendiri dan orang lain, B melakukan common humanity.

"Setiap kali berada dalam tekanan, saya berusaha untuk berpikir bahwa saya gak sendiri mengalami hal seperti ini, ada juga orang di luar sana yang kurang lebih mengalami hal yang saya alami dan mungkin bisa lebih buruk daripada apa yang telah saya alami di pekerjaan."

\title{
Partisipan D (Self-Compassion Tinggi)
}

Saat stres, D menghibur diri dengan berjalan-jalan bersama keluarga, merenungkan pencapaian diri, dan juga sembahyang. Sejauh yang disampaikan, partisipan menyatakan bahwa dirinya tidak melakukan aktivitas yang berdampak negatif terhadap dirinya secara fisik maupun psikologis, seperti sholat, istigfar, dan dzikir. Jawaban D mengindikasikan bahwa dirinya cenderung religius, sehingga terdapat kemungkinan itu menjadi salah satu faktor pendukung tingginya self-compassion D. Hal tersebut didukung penelitian Rahmah (2016) yang menemukan bahwa semakin religius individu, semakin tinggi self-compassion-nya.

\footnotetext{
"Saya kan beragama Islam, saya sendiri sih kalau berada di posisi stres karena gagal melakukan sesuatu dan lain-lain.. udah kembalikan kepada Allah."

"Misalnya habis selesai kerja melakukan hal-hal yang menyenangkan sama keluarga di rumah atau ya istigfar sama dzikir aja supaya pikiran tenang."
}

D mengontrol diri dan pikirannya tetap tenang, mengidentifikasi penyebab stres, serta memikirkan solusi untuk menghilangkan stresnya. Jika stres muncul akibat dirinya melakukan kesalahan atau kegagalan, maka D memikirkan hal positif dan memaafkan tanpa bersikap keras terhadap dirinya. Jika stres yang dirasakan disebabkan oleh orang lain, maka D berusaha memaklumi orang tersebut sebagai manusia yang 
tidak sempurna. D meyakini bahwa stres dalam hidupnya adalah pelajaran yang membuatnya menjadi bijaksana, sehingga ia lebih tenang. Reaksi tersebut merupakan self-kindness.

"Saya sih selalu berpikir bahwa tidak selalu diri kita ini bersih, semua orang juga pasti pernah melakukan kesalahanlah. Gak ada manusia yang gak luput dari kesalahan, ya wajar."

D berpikir objektif terlepas dari emosi pribadinya saat stres. D memikirkan cara yang tepat dilakukan untuk mengurangi stres, seperti menenangkan diri dan bersembahyang. Menurut $\mathrm{D}$, stres itu normal terjadi dalam hidup. Reaksi tersebut merupakan mindfulness.

\begin{abstract}
"Sejauh ini ketika saya stres ya tetap berpikir jernih. maksudnya, saya berusaha memahami apa yang membuat saya stres dan apa yang bisa saya lakukan untuk berhenti stres, mungkin semacam introspeksi diri juga kali. Kalau memang ternyata setelah dipikir-pikir kembali saya yang salah sehingga akhirnya stres saya akan berusaha supaya lebih menerima ketidaksempurnaan diri saya, tapi kalau karena orang lain saya juga bakal berusaha untuk memaklumi.. toh tiap manusia gak ada yang suci dari salah. Stres pasti berlalu. Saya gak akan stres terus-menerus.”
\end{abstract}

D menganggap setiap manusia tidak luput dari kekurangan, kesalahan, dan ketidaksempurnaan. Dari sejumlah pengalaman stres D selama bekerja sebagai perawat IGD, ia mampu menghubungkannya dengan pengalaman rekan kerjanya. Menurut D, stres yang dialaminya juga dirasakan oleh rekan kerjanya. Reaksi tersebut merupakan common humanity.

"Saya bisa merasakan stresnya teman-teman perawat di sini, mereka juga bisa merasakan stres saya. Kita sama-sama taulah bagaimana pekerjaan di sini, jadi kurang lebih pengalaman kita miriplah."

D terlihat cukup menonjolkan self-kindness, mindfulness, serta common humanity yang merupakan dimensi dari self-compassion. Sisi-sisi kebalikan dari dimensi self-compassion seperti self-judgement, over identification, dan isolation tidak menonjol.

\title{
Partisipan S (Self-Compassion Tinggi)
}

Saat stres, S menonton televisi, mencurahkan isi hati pada orang terdekat agar mendapat solusi stresnya, jalan-jalan bersama teman, dan bersembahyang. Aktivitas S tidak berisiko negatif terhadap kesehatan diri S, sehingga aktivitas tersebut digolongkan sebagai self-compassion. Menonton televisi merupakan aktivitas yang tidak banyak bergerak, sehingga cenderung memicu terjadinya obesitas (Rosiek, Maciejewska, Leksowski, Rosiek-Kryszewska, \& Leksowski, 2015). Akan tetapi, aktivitas menonton 
televisi S tidak diselingi dengan memakan camilan, sehingga masih dikategorikan sebagai selfcompassion,walaupun risiko negatif menonton televisi tetap dapat terjadi jika dilakukan secara berlebihan.

\begin{abstract}
"Berusaha untuk tidak stres terus menerus sepanjang waktu, berpikiran positif, kemudian sholat, kemudian curhat minta solusi sama ibu dan senior yang lebih bisa dipercaya di tempat kerja. Kan kita punya rekan kerja tuh di kerjaan yang lebih senior kan bisa dijadikan sebagai tempat curhatan yang bisa dipercayalah dan bisa kasih solusi, terus juga dengan teman-teman yang bisa kasih solusi yang terbaik.. kemudian ya dengan menghibur diri sendiri."

"Dengan cara memanjakan diri saya, dengan cara memanfaatkan waktu luang saya.. kayak misalnya nonton, kemudian jalan-jalan setelah seminggu bekerja, atau ke salon."
\end{abstract}

S mengontrol pikiran dan tindakannya untuk tetap tenang saat stres. S menenangkan diri dengan melakukan aktivitas yang disenanginya, mencari dukungan sosial dari orang terdekat, dan sembahyang. Setelah tenang, S memikirkan hal positif dari stres yang dialami sehingga lebih bisa memaklumi keadaan dan dirinya sendiri. Reaksi tersebut merupakan self-kindness.

S memandang stres secara objektif, sesuai realita, dan terlepas dari emosi pribadinya. S akan membuat dirinya tenang dan rileks sebelum berpikir secara objektif. S tidak pernah menyalahkan diri ataupun orang lain atas stres yang dialami serta tidak melebihkan ataupun larut dalam stres. Reaksi tersebut merupakan mindfulness.

"Mencoba berpikir bahwa tiap manusia itu tidak sempurna. Mungkin sulit ketika stres awal-awal ya.. tetapi setelah sudah tidak terlalu stres lagi ya bisa lebih objektif dalam memandang masalah yang saya alami biasanya."

S meyakini setiap manusia termasuk dirinya tidak luput dari kesalahan maupun kegagalan. Dari sejumlah pengalaman stres, S menganggap stres yang dirasakannya juga dirasakan oleh orang lain di sekitarnya, seperti orang tua dan rekan kerja. Dengan begitu, S merasa tidak sendirian bahkan bisa berbagi pengalaman dengan orang di sekitarnya. Reaksi tersebut merupakan common humanity.

"Saya sering berkonsultasi dengan ibu.. karena beliau kan lebih dulu menjadi perawat sehingga ya kurang lebih kejadian-kejadian di IGD ya serupa sih. Di ibu ada, teman-teman sesama perawat di sini juga ada baik yang senior maupun yang junior sih ya sama juga mengalami kejadian seperti itu."

S menunjukkan self-kindness, mindfulness, dan common humanity yang merupakan dimensi dari self-compassion. Akan tetapi, terkadang S menunjukkan sisi-sisi over identification, di mana ia merasa dirinya dipenuhi emosi ketika baru saja mendapatkan stres, sehingga agak sulit untuk dapat berpikir jernih 
di awal-awal mengalami stres. Meskipun demikian, S selalu berusaha untuk berpikir secara objektif ketika dirinya telah merasa tenang.

"Agak sulit juga sih. Gimana ya.. sulit sih ketika stres awal-awal, tapi setelah sudah tidak terlalu stres lagi ya bisa lebih objektif dalam mandang masalah yang saya alami biasanya."

\section{Rangkuman Hasil Analisis Ketiga Partisipan Penelitian}

Terdapat kecenderungan kesamaan dan perbedaan masing-masing partisipan. Saat stres, partisipan dengan self-compassion tinggi cenderung melakukan aktivitas positif yang tidak berdampak negatif terhadap kesehatan fisik maupun psikologis seperti sembahyang, jalan-jalan, serta mencari dukungan dari orang terdekat seperti keluarga, teman, dan rekan kerja. Sementara, partisipan dengan self-compassion rendah cenderung melakukan aktivitas pemanjaan diri atau self-indulgence, di mana berdampak negatif pada kesehatan, seperti menonton televisi dengan durasi panjang, bermain games, makan camilan, dan merokok.

Kesamaan aktivitas partisipan dengan self-compassion tinggi dan rendah adalah menonton televisi. Akan tetapi, menonton televisi pada partisipan dengan self-compassion tinggi tidak tergolong selfindulgence karena diselingi dengan memakan camilan. Durasi menonton televisi partisipan dengan selfcompassion rendah adalah seharian dan diselingi dengan memakan camilan, di mana berdasarkan penelitian, durasi menonton televisi berkorelasi positif dengan obesitas (Vioque, De Torres \& Quiles, 2000). Oleh sebab itu, menonton televisi partisipan dengan self-compassion rendah digolongkan sebagai selfindulgence.

Partisipan dengan self-compassion tinggi cenderung menunjukkan self-kindness setiap kali stres bekerja. Partisipan memberikan kehangatan pada diri sendiri, tidak menyalahkan diri, memaafkan kegagalan ataupun kesalahan yang diperbuat, menerima kekurangan diri dan menganggapnya sebagai suatu hal yang manusiawi dilakukan oleh semua manusia, serta menjadikan kesalahan ataupun kegagalan sebagai pembelajaran. Partisipan dengan self-compassion tinggi cenderung mengidentifikasi hal-hal yang dibutuhkan diri untuk mereduksi stres yang dialami. Partisipan dengan self-compassion rendah juga mampu menunjukkan self-kindness, namun cenderung tidak sebaik partisipan dengan self-compassion tinggi. Partisipan dengan self-compassion rendah memaafkan dan memberikan kehangatan pada diri sendiri jika kegagalan ataupun kesalahannya hanya melibatkan dirinya. Apabila berdampak negatif pada orang lain, maka ia sulit memaklumi dan memaafkan dirinya. Partisipan dengan self-compassion rendah cenderung menunjukkan ciri-ciri self-judgement dalam bentuk perasaan kesal, malu, kecewa, hingga menyalahkan diri 
sendiri ketika mengalami kegagalan ataupun melakukan kesalahan yang berdampak negatif pada pasien yang dirawat. Sementara itu, self-judgement tidak ditemukan pada partisipan dengan self-compassion tinggi.

Partisipan dengan self-compassion tinggi cenderung menunjukkan mindfulness dalam bentuk pengendalian emosi ketika sedang stres, menenangkan diri, mengontrol pikiran agar tidak larut dalam emosi negatif, tidak melebihkan-lebihkan masalah, tidak terus-menerus memikirkan stres, dan tidak larut dalam stres yang dirasakan. Partisipan dengan self-compassion tinggi selalu berusaha memikirkan solusi untuk mengatasi permasalahan dan stres yang dialami, serta beranggapan bahwa stres dapat melatih diri menjadi pribadi yang lebih kuat dan bijaksana. Sementara itu, partisipan dengan self-compassion rendah tidak ditemukan memiliki mindfulness.

Partisipan dengan self-compassion rendah cenderung menunjukkan over identification, di mana ia kesulitan berpikir jernih, dikuasai pikiran negatif, memikirkan masalah secara berlebihan, dan larut dalam stres. Salah satu partisipan dengan self-compassion tinggi juga menunjukkan over identification, di mana dirinya dipenuhi oleh emosi sesaat di awal-awal mengalami stres. Namun, partisipan dengan selfcompassion tinggi tetap berusaha menenangkan diri dengan sembahyang hingga dapat mengontrol diri dan berhasil mencapai mindfulness.

Partisipan dengan self-compassion tinggi dan rendah menyadari bahwa orang lain juga mengalami pengalaman stres seperti yang mereka alami. Ketiga partisipan menyadari bahwa orang tua, rekan kerja, teman, dan orang lain mengalami kegagalan dan kesalahan yang menyebabkan timbulnya stres. Hal tersebut menunjukkan bahwa common humanity tidak hanya dimiliki oleh individu dengan self-compassion tinggi saja, melainkan partisipan dengan self-compassion rendah pun dapat memiliki common humanity. Meskipun partisipan dengan self-compassion tinggi dan rendah menunjukkan common humanity, terdapat perbedaan di antaranya. Partisipan dengan self-compassion rendah terkadang cenderung berpikir bahwa orang di sekitarnya lebih bahagia daripada dirinya, sementara partisipan dengan self-compassion tinggi menganggap bahwa semua manusia merasakan stres maupun kebahagiaan yang serupa walau tak sepenuhnya.

Partisipan dengan self-compassion rendah cenderung isolation dengan menganggap orang di sekitarnya lebih bahagia daripada dirinya yang stres, meskipun di sisi lain ia mampu menghubungkan pengalamannya dengan orang lain. Sementara itu, partisipan dengan self-compassion tinggi cenderung tidak ditemukan memiliki isolation. 


\section{DISKUSI}

Mayoritas perawat IGD di Jakarta memiliki self-compassion yang cenderung tinggi. Padahal, penelitian serupa di Indonesia yang dilakukan Damayanti (2013), Kencana (2014), dan Novianty (2015) menunjukkan self-compassion perawat di Indonesia cenderung rendah. Terdapat kemungkinan adanya bias penelitian berupa social desirability, sehingga menyebabkan hasil self-compassion partisipan cenderung tinggi. Social desirability mungkin terjadi akibat kuesioner penelitian ini meminta partisipan untuk menuliskan nama jelas pada lembar inform consent. Partisipan mungkin memiliki keinginan untuk mendapatkan persetujuan dan penerimaan sosial, sehingga akhirnya memberikan jawaban yang memperlihatkan dirinya seolah-olah memiliki self-compassion tinggi. Menurut Johnson, Fendrich, dan Mackesy-Amiti (2012), ketika identitas diri partisipan tidak diminta atau bersifat anonim, maka partisipan akan memberikan jawaban tepat secara jujur. Dalam hal ini, penulisan identitas nama partisipan diminta untuk mempermudah pemilihan partisipan kualitatif.

Penelitian ini menemukan perawat IGD dengan self-compassion tinggi cenderung menunjukkan sisi religiusitas dengan sembahyang untuk memperoleh ketenangan saat mengalami stres. Dengan mendekatkan diri pada Tuhan, partisipan dengan self-compassion tinggi cenderung lebih dapat memaklumi kekurangan diri sendiri, sehingga berusaha untuk terus berpikir positif dan memperbaiki kekurangan diri. Rahmah (2016) menemukan bahwa religiusitas berkorelasi positif dengan self-compassion, di mana semakin religius individu, maka semakin tinggi self-compassion-nya. Sementara itu, perawat dengan selfcompassion rendah tidak terlihat melakukan kegiatan religius.

Ditemukan perbedaan self-compassion secara signifikan berdasarkan lama bekerja partisipan. Partisipan dengan lama bekerja 4-6 tahun memiliki self-compassion tertinggi dibandingkan partisipan dengan lama bekerja lainnya. Terjadinya peningkatan self-compassion pada lama bekerja kurang dari 1 tahun hingga 4-6 tahun dan penurunan self-compassion pada lama bekerja di atas 4-6 tahun. Peningkatan self-compassion pada partisipan dengan lama bekerja kurang daril tahun hingga 4-6 tahun, mungkin disebabkan oleh adanya minat bekerja partisipan. Sementara itu, penurunan self-compassion pada partisipan dengan lama bekerja lebih dari 10 tahun mungkin terjadi akibat adanya kejenuhan bekerja sama dengan yang dirasakan partisipan dengan lama bekerja di atas 4-6 tahun. Menurut Anies (2005), ada kalanya kejenuhan ditimbulkan oleh hal-hal yang semula dianggap mengasyikkan, namun lama-kelamaan berubah menjadi membosankan. Kejenuhan bekerja dapat dipicu oleh beban kerja yang tinggi, waktu kerja yang tidak teratur, jam kerja yang padat, rutinitas pekerjaan yang monoton, dan pekerjaan yang kompleks. 


\section{SIMPULAN DAN SARAN}

\section{Simpulan}

Berdasarkan hasil kuantitatif secara umum, self-compassion perawat IGD di Jakarta tergolong tinggi dengan rata-rata keseluruhan partisipan sebesar 3.57 dan hanya satu perawat yang memiliki selfcompassion rendah. Berdasarkan demografi, peneliti tidak menemukan perbedaan signifikan pada faktor jenis kelamin maupun usia partisipan, dan hanya menemukan perbedaan self-compassion signifikan pada lama masa bekerja. Self-compassion partisipan yang bekerja selama bekerja 4-6 tahun berbeda secara signifikan dengan partisipan yang bekerja selama lebih dari 10 tahun. Berdasarkan hasil perbandingan selfcompassion partisipan antar rumah sakit, ditemukan perbedaan yang signifikan, di mana self-compassion partisipan rumah sakit umum tipe B lebih tinggi daripada partisipan rumah sakit lainnya.

Berdasarkan hasil kualitatif, partisipan dengan self-compassion tinggi cenderung melakukan aktivitas positif dan religius yang tidak merugikan ataupun berdampak negatif pada diri sendiri, selfkindness, mindfulness, dan common humanity. Meskipun demikian, terdapat partisipan dengan selfcompassion tinggi yang melakukan over identification. Sementara itu, partisipan dengan self-compassion tinggi cenderung melakukan self-indulgence, self-judgement, over identification, dan terkadang isolation. Namun, partisipan dengan self-compassion rendah terkadang dapat melakukan self-kindness dan common humanity meskipun tidak sebaik partisipan dengan self-compassion tinggi.

\section{Saran Teoretis}

Penelitian serupa selanjutnya disarankan membangun rapport dengan partisipan agar terhindar dari kemungkinan social desirability atau dapat pula menggunakan kuesioner Marlowe-Crowne Social Desirability Scale, dan meneliti lebih lanjut faktor penyebab perbedaan self-compassion berdasarkan lama masa bekerja partisipan. Selain itu, perlu menyertakan data dari seluruh tipe rumah sakit secara lengkap agar mendapat gambaran self-compassion yang lebih menyeluruh. Data rumah sakit tipe A tidak diperoleh karena institusi peneliti belum memiliki perjanjian kerja sama dengan rumah sakit tipe A, sehingga peneliti tidak dapat melakukan penelitian di rumah sakit tersebut.

\section{Saran Praktis}

Perawat IGD di Jakarta dapat berbagi pengalaman dan saran untuk meningkatkan self-compassion kepada perawat lainnya yang masih memiliki self-compassion rendah. Selain itu, pihak rumah sakit di 
Jakarta perlu memperhatikan serta membantu meningkatkan self-compassion perawat IGD agar dapat bekerja secara maksimal dengan melakukan pelatihan self-compassion.

\section{UCAPAN TERIMA KASIH}

Peneliti mengucapkan terima kasih kepada pengelola rumah sakit yang telah memberikan izin kepada peneliti untuk melakukan penelitian, khususnya kepada kepala dan perawat IGD.

\section{REFERENSI}

Abaci, R., \& Arda, D. (2013). Relationship between self-compassion and job satisfaction in white collar workers. Procedia-Social and Behavioral Sciences, 106, 2241-2247. doi: 10.1016/j.sbspro.2013.12.255

Adhitya, K., \& Untoro, W. (2016). Kinerja klinis sebagai prediktor kepuasan pasien dengan moderasi prioritas kegawatan pasien. Jurnal Economia, 13(2), 155-170.

Algina, J., \& Crocker, L. (2008). Introduction to classical \& modern test theory. Mason, OH: Cengage Learning.

Anies. (2005). Penyakit akibat kerja. Jakarta: Elex Media Komputindo.

Badan Pusat Statistik. (2016). Jakarta dalam angka 2016. Jakarta: Author.

Beaumont. E., Carson. J., Durkin. M., \& Martin. H. (2016). Measuring relationships between selfcompassion, compassion fatigue, burnout and well-being in trainee counsellors and trainee cognitive behavioural psychotherapists: A quantitative survey. Journal of Counselling and Psychotherapy Research, 16(1), 15-23. doi: 10.1002/capr.12054

Brysiewicz, P., \& Wentzel, D. (2014). The consequence of caring too much: compassion fatigue and the trauma nurse. Journal of emergency nursing, 40(1), 95-97. doi: 10.1016/j.jen.2013.10.009

Craig. J., Hooper, C., Javrin. D. R., \& Reimels. E. (2010). Compassion satisfaction, burnout, and compassion fatigue among emergency nurses compared with nurse in other selected inpatient specialties. Journal of Emergency Nursing, 36(5), 420-427. doi: 10.1016/j.jen.2009.11.027

Creswell, J. W. (2012). Education research, planning, conducting and evaluating quantitative and qualitative research (4th ed.). Boston, MA: Pearson.

Damayanti, A. (2013). Studi deskriptif mengenai self-compassion pada perawat rumah sakit jiwa " $x$ ” kota Bandung (Skripsi tidak dipublikasikan). Universitas Kristen Maranatha, Indonesia. 
Dinas Kesehatan Provinsi DKI Jakarta. (2016). Profil kesehatan provinsi DKI Jakarta tahun 2015. Jakarta: Kementerian Kesehatan Republik Indonesia.

Johnson, T, P., Fendrich, M., \& Mackesy-Amiti, M. E. (2012). A validation of the Crowne-Marlowe social desirability scale. Quality and Quantity, 46(6), 1661-1666. doi: 10.1007/s11135-0119563-5

Kementerian Kesehatan Republik Indonesia. (2012). Pedoman pencegahan dan penanggulangan kegemukan dan obesitas pada anak sekolah. Jakarta: Kementerian Kesehatan RI.

Kencana, S, P. (2014). Self-compassion pada perawat di rumah sakit 'x' kota Bandung (Skripsi tidak dipublikasikan). Universitas Maranatha, Indonesia.

Lumintang, P., Kumaat, L., \& Mulyadi, N. (2015). Perbedaan tingkat stres perawat instalasi gawat darurat dan unit rawat inap di Rumah Sakit Pancaran Kasih GMIM Manado. Jurnal Keperawatan, 3(1), 1-6.

Mallya. A., Rachmadi. F., \& Hafizah. R. (2016). Perbedaan stres kerja antara perawat Instalasi Gawat Darurat (IGD) dan perawat Intensive Care Unit (ICU) RSUD Sultan Syarif Mohamad Alkaried kota Pontianak (Skripsi tidak dipublikasikan). Universitas Tanjungpura, Indonesia.

Mandasari, T., Choiri, M., \& Sari, R. A. (2014). Analisa beban kerja perawat UGD menggunakan Malasch burnout inventory dan modifikasi heart. Jurnal Rekayasa dan Manajemen Sistem Industri, 2(5), 1044-1054.

Mansour, A. M. H., \& Ratrout. H. F. (2017). Factors associated with secondary traumatic stress among emergency nurses: An integrative review. Open Journal of Nursing, 7(11), 1209-1226. doi: 10.4236/ojn.2017.711088

Menteri Kesehatan Republik Indonesia. (2010). Peraturan menteri kesehatan republik Indonesia nomor 340/menkes/per/iii/2010. Ditemu kembali dari http://pelayanan.jakarta.go.id/download/regulasi/peraturan-menteri-kesehatannomor-340-tentang-klasifikasi-rumah-sakit.pdf

Mustafidz, \& Mustikasari. (2013). Faktor-faktor stres kerja perawat di ruang IGD RSUD (emergency setting) Cibinong (Skripsi tidak dipublikasikan). Universitas Indonesia, Indonesia.

Nolen-Hoeksema, S., Wisco, B. E., \& Lyubomirsky, S. (2008). Rethink rumination. Perspectives on Psychological Science, 3(5), 400-424. doi:10.1111/j.1745-6924.2008.00088.x

Neff, K. D. (2003a). The development and validation of a scale to measure self-compassion. Self and Identity, 2, 223-250. doi: 10.1080/15298860390209035 
Neff, K. D. (2003b). Self-compassion: An alternative conceptualization of a healthy attitude toward oneself. Self and Identity, 2, 85-101. doi: 10.1080/15298860390129863

Nugraha, A. R. A. (2017). Pengaruh locus of control dan self-compassion terhadap kinerja auditor: Survey pada perwakilan badan pengawasan keuangan dan pembangunan provinsi Sulawesi Selatan (Naskah tidak dipublikasikan). Universitas Hasanuddin, Indonesia.

Novianty, S, R. (2015). Self-compassion pada perawat ruang rawat inap di RSUD “ $x$ ” di kota “ $y$ ”(Skripsi tidak dipublikasikan). Universitas Kristen Maranatha, Indonesia.

Prasetyo, W. (2017). Literature review: Stres perawat di ruang instalasi gawat darurat. Jurnal Ners Lentera, $5(1), 43-55$.

Rahmah, I. (2016). Hubungan antara religiusitas dengan self-compassion pada remaja. (Skripsi tidak dipublikasikan). Universitas Padjajaran, Indonesia.

Rahman, H. (2013). Hubungan faktor stres kerja dengan kinerja perawat di instalasi gawat darurat rumah sakit primer Surabaya (Skripsi tidak dipublikasikan). Universitas Airlangga, Indonesia.

Rosiek, A., Maciejewska, N, F., Leksowski, K., Rosiek-Kryszewska, A., \& Leksowski, L. (2015). Effect of television on obesity and excess of weight and consequences of health. International Journal of Environment Research and Public Health, 12(8), 9408-9426. doi: 10.3390/ijerph120809408

Saminan. (2016). Efek perilaku merokok terhadap saluran pernafasan. Journal Kedokteran Syiah Kuala, 16(3), 191-194.

Suardani, L. (2016). Hubungan antara beban kerja dengan kepuasan kerja perawat di IGD RSUD kabupaten Buleleng tahun 2015. (Skripsi tidak dipublikasikan). Universitas Udayana, Indonesia.

Vioque, J., De Torres, A., \& Quiles, J. A. (2000). Time spent watching television, sleep duration and obesity in adults living in Valencia, Spain. International Journal of Obesity, 24(12), 1683-1688. 